\title{
FORECASTING JUMLAH MAHASISWA BARU MENGGUNAKAN METODE AUTOMATIC CLUSTERING AND FUZZY LOGIC RELATIONSHIP MARKOV CHAIN (STUDI KASUS : FAKULTAS TEKNOLOGI INFORMASI DAN KOMUNIKASI VISUAL INSTITUT SAINS DAN TEKNOLOGI AL-KAMAL)
}

\author{
Mundirin \\ Prodi Sistem Informasi Fakultas Teknologi Informasi dan KomunikasiVisual \\ Institut Sains dan Teknologi Al-Kamal \\ Email:mundirin83@gmail.com
}

\begin{abstract}
Abstraksi
Forecasting atau peramalan merupakan suatu teknik analisa perhitungan yang dilakukan dengan melakukan pendekatan kualitatif maupun kuantitatif untuk memperikirakan kejadian dimasa depan dengan menggunakan referensi data dimasa lalu. Tujuan dari penelitian ini adalah melakukan prediksi jumlah mahasiswa baru di Fakultas Teknologi Informasi dan Komunikasi Visual Institut Sains dan Teknologi Al-Kamal tahun ajaran 2020/2021. Prediksi jumlah mahasiswa baru di Fakultas Teknologi Informasi dan Komunikasi Visual Institut Sains dan Teknologi Al-Kamal dimasa yang akan datang secara akurat sangat penting dilakukan, karena banyak keputusan yang bisa diambil oleh Pimpinan Institut Sains dan Teknologi Al-Kamal dari prediksi tersebut. Metode Automatic Clustering and Fuzzy Logic Relationship Markov Chain dipilih karena memiliki tingkat akurasi yang lebih baik diantara metode-metode Fuzzy Logic lainnya. Data yang digunakan dalam penelitian ini adalah data sekunder yang diperoleh dari Sistem Informasi Akademik Institut Sains dan Teknologi Al-Kamal. Berdasarkan penelitian ini diperoleh bahwa hasil prediksi jumlah mahasisawa baru Fakultas Teknologi Informasi dan Komunikasi Visual Institut Sains dan Teknologi Al-Kamal tahun ajaran 2020/2021 sebesar 64 dengan MAPE sebesar 8,25\%
\end{abstract}

Kata Kunci : Forecasting,metode, Automatic Clustering and Fuzzy Logic Relationship Markov Chain

\begin{abstract}
Forecasting or forecasting is a calculation analysis technique that is done by carrying out qualitative and quantitative approaches to think about future events using reference data in the past. The purpose of this study is to predict the number of new students at the Faculty of Information and Visual Communication Technology at the Al-Kamal Institute of Science and Technology in the academic year 2020/2021. Prediction of the number of new students in the Faculty of Information and Visual Communication Technology of the Al-Kamal Institute of Science in the future accurately is very important to do, because many decisions can be taken by the Leaders of the Al-Kamal Institute of Science and Technology from these predictions. Markov Chain Automatic Clustering and Fuzzy Logic Relationship Method was chosen because it has a better level of accuracy among other Fuzzy Logic methods. The data used in this study are secondary data obtained from the Academic Information System of the Al-Kamal Institute of Science and Technology. Based on this research it was found that the predicted results of the number of new students of the Faculty of Information and Visual Communication Technology at the Al-Kamal Institute of Science and Technology in the academic year 2020/2021 amounted to 64 with a MAPE of $8.25 \%$
\end{abstract}

Keywords: Forecasting,metode, Automatic Clustering and Fuzzy Logic Relationship Markov Chain 


\section{Pendahuluan}

Prediksi atau peramalan suatu data sering kali dibutuhkan untuk melakukan perencaanaan dan strategi dalam pengambilan suatu keputusan. Peramalan dilakukan berdasarkan data masa lampau yang dianalisis dengan menggunakan metode tertentu. Jumlah mahasiswa baru Fakultas Teknologi Informasi dan Komunikasi Visual Institut Sains dan Teknologi Al-Kamal tiga tahun terakhir mengalami penurunan yang signifikan. Pada tahun 2018 jumlah mahasiswa baru Fakultas Teknologi Informasi dan Komunikasi Visual mengalami penurunan sebesar 20\% kemudian pada tahun 2018 jumlah mahasiswa baru Farmasi mengalami penurunan sebesar 40\%. Dalam situasi ini prediksi diperlukan untuk menyelesaikan permasalahan tersebut. Salah satunya adalah membuat strategi pemasaran atau promosi yang tepat sehingga jumlah pendaftar mahasiswa baru bertambah.

Berdasarkan penelitian-penelitian sebelumnya di peroleh kesimpulan bahwa metode Automatic Clustering and Fuzzy Logic Relationship Markov Chain memiliki tingkat akurasi lebih baik dibandingkan metode yang lain. Oleh karena itu pada penelitian ini akan melakukan prediksi jumlah mahasiswa baru Farmasi Institut Sains dan Teknologi Al-Kamal tahun ajaran 2020/2021 menggunakan metode Automatic Clustering and Fuzzy Logic Relationship Markov Chain dipilih agar hasil prediksi memiliki tingkat akurasi yang tinggi.

\section{Metode Penelitian}

Metode yang digunakan dalam penelitian ini adalah kuantitatif, data yang digunakan adalah data sekunder yang diambil dari sistem informasi Akademik Institut Sains dan Teknologi Al-Kamal. Data yang digunakan merupakan data jumlah mahasiswa baru tahun ajaran akademik 2010 Gasal sampai dengan tahun ajaran akademik 2019 Genap.

Langkah-langkah prediksi metode Automatic Clustering and Fuzzy Logic Relationship Markov Chain. Tahap 1 : Menerapkan Automatic Clustering

Tahap 2 : Mengasumsikan bahwa terdapat $n$ interval $\mathrm{u}_{1}, \mathrm{u}_{2}, \mathrm{u}_{3}, \ldots \mathrm{u}_{\mathrm{n}}$ kemudian mendefinisikan setiap himpunan fuzzy $\mathrm{A}_{i}$ dimana $1 \leq i \leq \mathrm{n}$.

Tahap 3 : Fuzzifikasi setiap data dalam data historis menjadi himpunan fuzzy

Tahap 4 : Membuat Relasi Fuzzy dan kelompok relasi fuzzy

Tahap 5 : Menghitung nilai peramalan berdasarkan pada kelompok relasi fuzzy dan matrik probabilitas transisi state Markovnya.

Tahap 6: Menyesuaikan kecenderungan nilai peramalan Hubungan antara state-state

Tahap 7 : Menentukan Hasil peramalan

Tahap 8 : Menghitung nilai MAPE.

\section{Hasil dan Pembahasan}

\section{Jumlah Mahasiswa Baru Fakultas Teknologi Informasi dan Komunikasi Visual

\author{
- Teknik Informatika \\ Sistem Infromasi \\ DKV \\ - Total Jumlah Mahasiswa Baru
}

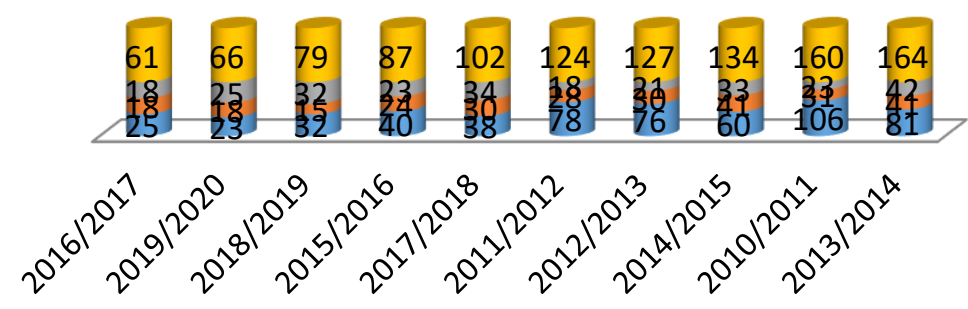

Gambar 1. Jumlah mahasiswa Baru FTIKV 
Tahap penggunaan metode Automatic Clustering and Fuzzy Logic Relationship Markov Chain sebagai berikut: Tahap 1 : Menerapkan Automatic Clustering

Dalam Tahap melakukan automaticclustering langkah-langkahmya adalah sebagai berikut.

1. Menyortir data jumlah mahasiswa baru ftikv Institut Sains dan Teknologi Al-Kamal mulai tahun ajaran 2010/2011 sampai dengan 2019/2020 dari data yang paling kecil ke paling besar kemudian dicari ratarata selisihnya (average_diff) dan diperoleh nilai average_diff nya adalah 10,4.

2. Membentuk cluster-cluster berdasarkan nilai average_diff Cluster $1:\{61,66\} \quad$ cluster $2:\{79,87\}$ cluster $3:\{102\}$

Cluster $4:\{124,127,134\}$ cluster $5:\{160,164\}$

3. Berdasarkan hasil langkah ke-2 selanjutnya adalah menyusun kemabali cluster-cluster tersebut berdasarkan langkah 2.3 prinsip 1, prinsip 2 dan prinsip 3 sehingga diperoleh cluster-cluster berikut. Cluster $1:\{61,66\} \quad$ cluster $2:\{79,87\}$ cluster $3:\{102\}$

Cluster $4:\{124,134\}$ cluster $5:\{160,164\}$

4. Mentransformasikancluster-cluster hasil langkah ke-3 kedalam interval berdasarkan sub langkah 4.1, 4.2 dan 4.3, sehingga diperoleh interval-interval berikut.
a. $[61 ; 66)$
e. $[102 ; 124)$
b. $[66 ; 79)$
f. $[124 ; 134)$
c. $[79 ; 87)$
g. $[134 ; 160)$
d. $[87 ; 102)$
h. $[160 ; 164)$

5. Membagi setiap interval menjadi $p$ sub-interval. Semakin besar nilai $p$ maka semakin akurat hasil peramalannya. Dalam penelitian ini diambil nilai $p=2$, sehingga diperoleh interval baru sekaligus mid point nya sebagai berikut.

$\begin{array}{llll}\mathrm{U}_{1}=[61 ; 63,5) & \mathrm{M}_{1}=62,5 & \mathrm{U}_{9}=[102 ; 113) & \mathrm{M}_{9}=107,5 \\ \mathrm{U}_{2}=[63,5 ; 66) & \mathrm{M}_{2}=64,75 & \mathrm{U}_{10}=[113 ; 124) & \mathrm{M}_{10}=118,5 \\ \mathrm{U}_{3}=[66 ; 72,5) & \mathrm{M}_{3}=69,25 & \mathrm{U}_{11}=[124 ; 129) & \mathrm{M}_{11}=126,5 \\ \mathrm{U}_{4}=[72,5 ; 79) & \mathrm{M}_{4}=75,75 & \mathrm{U}_{12}=[129 ; 134) & \mathrm{M}_{12}=131,5 \\ \mathrm{U}_{5}=[79 ; 83) & \mathrm{M}_{5}=81 & \mathrm{U}_{13}=[134 ; 147) & \mathrm{M}_{13}=140,5 \\ \mathrm{U}_{6}=[83 ; 87) & \mathrm{M}_{6}=85 & \mathrm{U}_{14}=[147 ; 160) & \mathrm{M}_{14}=153,5 \\ \mathrm{U}_{7}=[87 ; 94,5) & \mathrm{M}_{7}=90,75 & \mathrm{U}_{15}=[160 ; 162) & \mathrm{M}_{15}=161 \\ \mathrm{U}_{8}=[94,5 ; 102) & \mathrm{M}_{8}=98,25 & \mathrm{U}_{16}=[162 ; 164) & \mathrm{M}_{16}=163\end{array}$

Tahap 2 : Mengasumsikan bahwa terdapat $n$ interval $\mathrm{u}_{1}, \mathrm{u}_{2}, \mathrm{u}_{3}, \ldots \mathrm{u}_{\mathrm{n}}$ kemudian mendefinisikan setiap himpunan fuzzy $\mathrm{A}_{i}$ dimana $1 \leq i \leq \mathrm{n}$.

Dalam proses fuzzifikasi terdapat 16 interval $\mathrm{U}_{1}, \mathrm{U}_{2}, \mathrm{U}_{3} \ldots \ldots \mathrm{U}_{16}$ kemudian mendefinisikan setiap himpunan fuzzy $\mathrm{A}_{i}$ dimana $1 \leq i \leq 16$.

$\mathrm{A}_{1}=\left\{1 / \mathrm{U}_{1}, 0,5 / \mathrm{U}_{2}, 0 / \mathrm{U}_{3}, 0 / \mathrm{U}_{4}, 0 / \mathrm{U}_{5}, 0 / \mathrm{U}_{6}, 0 / \mathrm{U}_{7}, 0 / \mathrm{U}_{8}, 0 / \mathrm{U}_{9}, 0 / \mathrm{U}_{10}, 0 / \mathrm{U}_{11}, 0 / \mathrm{U}_{12}, 0 / \mathrm{U}_{13}, 0 / \mathrm{U}_{14}, 0 / \mathrm{U}_{15}, 0 / \mathrm{U}_{16}\right\}$

$\mathrm{A}_{2}=\left\{0,5 / \mathrm{U}_{1}, 1 / \mathrm{U}_{2}, 0,5 / \mathrm{U}_{3}, 0 / \mathrm{U}_{4}, 0 / \mathrm{U}_{5}, 0 / \mathrm{U}_{6}, 0 / \mathrm{U}_{7}, 0 / \mathrm{U}_{8}, 0 / \mathrm{U}_{9}, 0 / \mathrm{U}_{10}, 0 / \mathrm{U}_{11}, 0 / \mathrm{U}_{12}, 0 / \mathrm{U}_{13}, 0 / \mathrm{U}_{14}, 0 / \mathrm{U}_{15}, 0 / \mathrm{U}_{16}\right\}$

$\mathrm{A}_{3}=\left\{0 / \mathrm{U}_{1}, 0,5 / \mathrm{U}_{2}, 1 / \mathrm{U}_{3}, 0,5 / \mathrm{U}_{4}, 0 / \mathrm{U}_{5}, 0 / \mathrm{U}_{6}, 0 / \mathrm{U}_{7}, 0 / \mathrm{U}_{8}, 0 / \mathrm{U}_{9}, 0 / \mathrm{U}_{10}, 0 / \mathrm{U}_{11}, 0 / \mathrm{U}_{12}, 0 / \mathrm{U}_{13}, 0 / \mathrm{U}_{14}, 0 / \mathrm{U}_{15}, 0 / \mathrm{U}_{16}\right\}$

....

$\ddot{A}_{16}=\left\{0 / U_{1}, 0,5 / U_{2}, 0 / U_{3}, 0 / U_{4}, 0 / U_{5}, 0 / U_{6}, 0 / U_{7}, 0 / U_{8}, 0 / U_{9}, 0 / U_{10}, 0 / U_{11}, 0 / U_{12}, 0 / U_{13}, 0 / U_{14}, 0,5 / U_{15}, 1 / U_{16}\right\}$

Tahap 3 : Fuzzifikasi setiap data dalam data historis menjadi himpunan fuzzy

Data historis pendaftar mahasiswa baru FTIKV Institut Sains dan Teknologi Al-Kamal difuzzyfikasi dan dapat dilihat hasil tabel berikut.

Tabel 1. Data historis pendaftar mahasiswa baru FTIKV

\begin{tabular}{|l|l|l|l|r|l|}
\hline $\begin{array}{l}\text { Tahun } \\
\text { Ajaran }\end{array}$ & $\begin{array}{l}\text { Jumlah } \\
\text { Pendaftar }\end{array}$ & Fuzzyfikasi & $\begin{array}{l}\text { Tahun } \\
\text { Ajaran }\end{array}$ & Tahun Ajar & Fuzzyfikasi \\
\hline $2010 / 2011$ & 160 & A15 & $2015 / 2016$ & 87 & A7 \\
\hline $2011 / 2012$ & 124 & A11 & $2016 / 2017$ & 61 & A1 \\
\hline $2012 / 2013$ & 127 & A11 & $2017 / 2018$ & 102 & A9 \\
\hline $2013 / 2014$ & 164 & A16 & $2018 / 2019$ & 79 & A5 \\
\hline $2014 / 2015$ & 134 & A13 & $2019 / 2020$ & 66 & A3 \\
\hline
\end{tabular}


Tahap 4 : Membuat Relasi Fuzzy dan kelompok relasi fuzzy

Membuat relasi fuzzy, misalnya relasi fuzzy antara tahun ajaran 2010/2011 dengan 2019/2020 dikonstruksikan menjadi , dan seterusnya dimana hasil lengkap dapat dilihat dalam Tabel berikut.

Tabel 2. Relasi Fuzzy dan kelompok relasi fuzzy

\begin{tabular}{|l|r|r|l|l|l|}
\hline $\begin{array}{l}\text { Tahun } \\
\text { Ajaran }\end{array}$ & Fuzzyfikasi & Relasi Fuzzy & $\begin{array}{l}\text { Tahun } \\
\text { Ajaran }\end{array}$ & Fuzzyfikasi & $\begin{array}{l}\text { Relasi } \\
\text { Fuzzy }\end{array}$ \\
\hline $2010 / 2011$ & A15 & A15 $\rightarrow$ A11 & $2015 / 2016$ & A7 & A7 $\rightarrow$ A1 \\
\hline $2011 / 2012$ & A11 & A11 $\rightarrow$ A11 & $2016 / 2017$ & A1 & A1 $\rightarrow$ A9 \\
\hline $2012 / 2013$ & A11 & A1 $\rightarrow$ A16 & $2017 / 2018$ & A9 & A9 $\rightarrow$ A5 \\
\hline $2013 / 2014$ & A16 & A16 $\rightarrow$ A13 & $2018 / 2019$ & A5 & A5 $\rightarrow$ A3 \\
\hline $2014 / 2015$ & A13 & A13 $\rightarrow$ A 7 & $2019 / 2020$ & A3 & A3 $\rightarrow \neq$ \\
\hline
\end{tabular}

Relasi fuzzy tersebut kemudian dikelompokkan dimana relasi fuzzy yang sama dimasukkan kedalam kelompok relasi fuzzy yang sama.

Kelompok $1:$ A1 $\rightarrow$ A9

Kelompok $2:$ A $3 \rightarrow \neq$

Kelompok $3:$ A5 $\rightarrow$ A3

Kelompok $4:$ A7 $\rightarrow$ A1

Kelompok $5:$ A9 $\rightarrow$ A5

Tahap 5 : Menghitung nilai peramalan berdasarkan pada kelompok relasi fuzzy dan matrik probabilitas transisi state Markovnya.

$\mathrm{R}=\left(\begin{array}{ccc}0,5 & \cdots & 0 \\ \vdots & \ddots & \vdots \\ 0 & \cdots & 0\end{array}\right)$

Tahap 6 : Menyesuaikan kecenderungan nilai peramalan Hubungan antara state-state Matriks probabilitas transisi state markov dapat digambarkan sebagai berikut

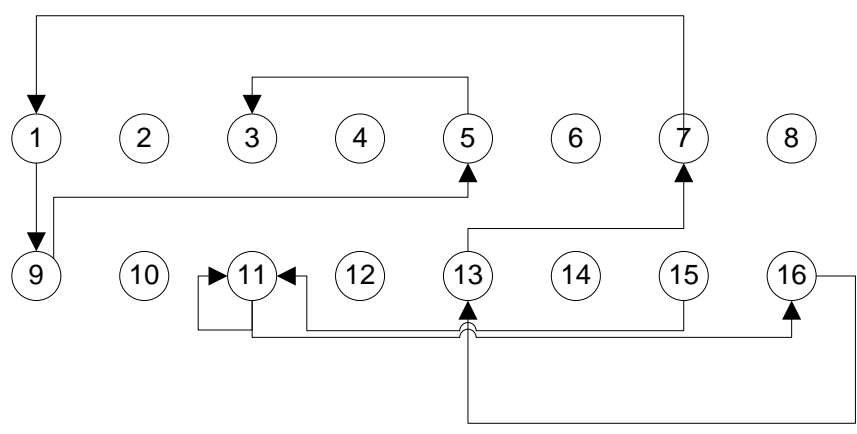

Gambar 2. Rantai Markov transisi Peramalan data Historis

Tahap 7 : Menentukan Hasil peramalan

Tabel 3. Hasil Peramalan

\begin{tabular}{|l|l|l|l|l|}
\hline Tahun Ajaran & $\begin{array}{l}\text { Data aktual } \\
\text { jumlah mahasiswa } \\
\text { baru }\end{array}$ & Prediksi & Nilai Penyesuaian & $\begin{array}{l}\text { Prediksi yang } \\
\text { sudah disesuaikan }\end{array}$ \\
\hline $2010 / 2011$ & 160 & - & - & - \\
\hline $2011 / 2012$ & 124 & 126,5 & 0 & 126,5 \\
\hline
\end{tabular}




\begin{tabular}{|l|r|l|l|l|}
\hline $2012 / 2013$ & 127 & 130 & 30 & 130 \\
\hline $2013 / 2014$ & 164 & 163 & 0 & 163 \\
\hline $2014 / 2015$ & 134 & 140,5 & 0 & 140,5 \\
\hline $2015 / 2016$ & 87 & 90,75 & 0 & 90,75 \\
\hline $2016 / 2017$ & 61 & 62,5 & 0 & 62,5 \\
\hline $2017 / 2018$ & 102 & 107,5 & 0 & 107,5 \\
\hline $2018 / 2019$ & 79 & 81 & 0 & 81 \\
\hline $2019 / 2020$ & 66 & 64,75 & 0 & 64,75 \\
\hline $2020 / 2021$ & - & 64,75 & 0 & 64,75 \\
\hline
\end{tabular}

Dari Tabel diata dapat dilihat bahwa hasil prediksi jumlah mahasiswa baru FTIKV ISTA tahun ajaran 2020/2021 adalah 64,75.

Tahap 8 : Menghitung nilai MAPE.

Berdasarkan hasil prediksi dalam Tabel diatas dapat dihitung nilai MAPE-nya sebagai berikut.

MAPE $=\sum_{t=1}^{n}=\frac{\frac{X t-F t}{X t}}{\mathrm{n}} X 100 \%=8,25 \%$

\section{Kesimpulan}

Berdasarkan penelitian diperoleh hasil prediksi jumlah pendaftar calon mahasiswa baru Fakultas Teknologi Informasi Komunikasi Visual (FTIKV) Institut Sains dan Teknologi Al-Kamal sebesar 64 orang dengan eror peramalanya MAPE sebesar 8,25\%. setiap interval menjadi $p$ sub-interval. Semakin besar nilai $p$ maka semakin akurat hasil peramalannya. Dalam penelitian ini diambil nilai $p=2$ sehingga hasil untuk variable $\mathrm{M}$ tidak bisa lebih dari 165 .

\section{Daftar Pustaka}

[1] Chen, S. M., Hsu, C. C. 2004. A New Method to Forecast Enrollments Using Fuzzy Time Series. Vol.2, No.3, pp.234-244.

[2] Eko, Haryono. 2013. Kajian model Automatic Clustering-Fuzzy Time Series-Markov Chain dalam memprediksi data historis jumlah kecelakaan lalu lintas di kota Malang. Jurnal Sains Dasar. Vol.1, No.2, pp.63-71

[3] Nurmalitasari, Sri Sumarlinda.2016. Peramalan Jumlah Pendaftar mahasiswa baru STMIK Duta Bangsa Surakarta menggunakan metode Automatic Cluster Clustering and Fuzzy Logic Relationship Markov Chain. Seminar Nasional Matematika. ISSN 2528-4630

[4] Rumondang, M. S. 2014. Peramalan Jumlah Mahasiswa Pendaftar Jurusan Matematika menggunakan Metode Automatic Clustering Dan Relasi Logika. Skripsi. Universitas Negeri Medan.

\section{Biodata Penulis}

Mundirin, memperoleh gelar Sarjana Ilmu Komputer (S.Kom), Program Studi Ilmu Komputer Universitas Komputer Indonesia(UNIKOM), lulus tahun 2010. Tahun 2014 memperoleh gelar Magister Komputer (M.Kom) dari Program Studi Sistem Informasi, STMIK Likmi. Saat ini sebagai Staf Pengajar di Program Studi Sistem Informasi Institut Sains dan Teknologi Al-Kamal Jakarta. 